\title{
An evaluation of the polymorphisms Ins I 6bp and Arg72Pro in p53 as breast cancer risk modifiers in BRCAI and BRCA2 mutation
}

\section{carriers}

\begin{abstract}
A Osorio*,1, M Pollán ${ }^{2}$, G Pita ${ }^{3}$, RK Schmutzler ${ }^{4}$, B Versmold ${ }^{4}$, C Engel $^{5}$, A Meindl ${ }^{6}$, N Arnold ${ }^{7}$, S Preisler-Adams ${ }^{8}$, D Niederacher ${ }^{9}$, W Hofmann ${ }^{10}$, D Gadzicki $^{11}$, A Jakubowska ${ }^{12}$, U Hamann ${ }^{13}$, J Lubinski ${ }^{12}$,

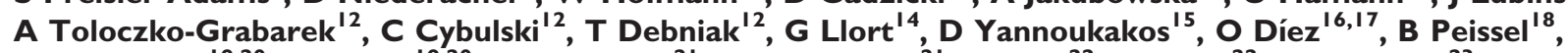
P Peterlongo ${ }^{19,20}$, P Radice ${ }^{19,20}$, T Heikkinen ${ }^{21}$, H Nevanlinna ${ }^{21}$, PL Mai ${ }^{22}$, JT Loud ${ }^{22}$, L McGuffog ${ }^{23}$, AC Antoniou ${ }^{23}$ and J Benitez ${ }^{1,3}$ on behalf of CIMBA
\end{abstract}

\begin{abstract}
'Human Cancer Genetics Programme, Human Genetics Group, Spanish National Cancer Centre (CNIO), Madrid, Spain; ${ }^{2}$ National Epidemiology Centre, Instituto de Salud Carlos III \& CIBERESP, Madrid, Spain; ${ }^{3}$ Human Cancer Genetics Programme, Genotyping Unit, Spanish National Cancer Centre (CNIO), Madrid, Spain; ${ }^{4}$ Division of Molecular Gynaeco-Oncology, Department of Obstetrics and Gynaecology, University of Cologne, Cologne, Germany; ${ }^{5}$ Institute for Medical Informatics, Statistics and Epidemiology, University of Leipzig, Leipzig, Germany; ${ }^{6}$ Department of Obstetrics and Gynaecology, Technical University, Munich, Germany; ${ }^{7}$ Department of Obstetrics and Gynaecology, University of Schleswig-Holstein, Campus Kiel, Germany; ${ }^{8}$ Institute of Human Genetics, University of Münster, Münster, Germany; ${ }^{9}$ Department of Obstetrics and Gynaecology, Molecular Genetics Laboratory, University of Düsseldorf, Düsseldorf, Germany; 'Onstitute of Human Genetics, Charite-University Medical Centre, Berlin, Germany; "Institute of Cellular and Molecular Pathology, Medical University, Hannover, Germany; ${ }^{12}$ Department of Genetics and Pathology, Pomeranian Medical University, Szczecin, Poland; ${ }^{13}$ German Cancer Research Center, Molecular Genetics of Breast Cancer, Heidelberg, Germany; ${ }^{14}$ Cancer Genetic Counselling Progam, Catalan Institute of Oncology (ICO), Barcelona, Spain; ${ }^{15}$ Molecular Diagnostics Laboratory IRRP, NCSR Demokritos, Athens, Greece; ${ }^{16}$ Genetics Service, Hospital de Sant Pau, Barcelona, Spain; ${ }^{17}$ Oncogenetics Laboratory, Hospital Vall d'Hebron, Barcelona, Spain; ${ }^{18}$ Medical Genetics Service, Fondazione IRCCS Istituto Nazionale dei Tumori, Milan, Italy; ${ }^{19}$ Unit of Genetic Susceptibility to Cancer, Department of Experimental Oncology, Fondazione IRCCS Istituto Nazionale dei Tumori, Milan, Italy; ${ }^{20}$ IFOM, Fondazione Istituto FIRC di Oncologia Molecolare, Milan, Italy; ${ }^{21}$ Department of Obstetrics and Gynecology, Helsinki University Central Hospital (HUCH), Helsinki, Finland; ${ }^{22}$ Clinical Genetics Branch, Division of Cancer Epidemiology and Genetics, National Cancer Institute, NIH, DHHS, Bethesda, MD, USA; ${ }^{23}$ Cancer Research UK Genetic Epidemiology Unit, Department of Public Health and Primary Care, University of Cambridge, Cambridge, UK
\end{abstract}

The close functional relationship between p53 and the breast cancer susceptibility genes BRCAI and BRCA2 has promoted the investigation of various polymorphisms in the $p 53$ gene as possible risk modifiers in BRCAI/2 mutation carriers. Specifically, two polymorphisms in p53, c.97-147ins I 6bp and p.Arg72Pro have been analysed as putative breast cancer susceptibility variants, and it has been recently reported that a 553 haplotype combining the absence of the 16 -bp insertion and the presence of proline at codon 72 (No Ins-72Pro) was associated with an earlier age at the onset of the first primary tumour in BRCA2 mutation carriers in the Spanish population. In this study, we have evaluated this association in a series of 2932 BRCAI/2 mutation carriers from the Consortium of Investigators of Modifiers of BRCAI and BRCA2.

British Journal of Cancer (2008) 99, 974-977. doi:I 0.I038/sj.bjc.6604624 www.bjcancer.com

(C) 2008 Cancer Research UK

Keywords: BRCA /; BRCA2; p53; breast cancer

Given the involvement of $p 53$ in cell cycle control, DNA repair and apoptosis, the role of this gene in cancer susceptibility has been extensively studied. Specifically, two polymorphisms in $p 53$, c.97-147ins16bp and p.Arg72Pro have been analysed as putative breast cancer susceptibility variants, although not all studies have yielded consistent results (Weston et al, 1997; Wang-Gohrke et al, 1998; Suspitsin et al, 2003; Damin et al, 2006; Baynes et al, 2007; Costa et al, 2008). The Arg72Pro single-nucleotide polymorphism

*Correspondence: Dr A Osorio, Human Genetics Group, Spanish National Cancer Centre (CNIO), C/Melchor Fernández Almagro 3, 28029 Madrid, Spain; E-mail: aosorio@cnio.es

Received 4 July 2007; accepted 30 July 2008
(SNP) has gained special attention, as there is consistent evidence of functional differences in apoptotic rates between the Arg and Pro variants (Biros et al, 2002; Wu et al, 2002; Dumont et al, 2003). In addition, the close functional relationship between $p 53$ and the breast cancer susceptibility genes $B R C A 1$ and $B R C A 2$ (Jonkers et al, 2001; Ongusaha et al, 2003; Liu et al, 2007) has promoted the investigation of the Arg72Pro SNP as a possible risk modifier in BRCA1/2 mutation carriers (Martin et al, 2003). Indeed, it was recently reported that a $p 53$ haplotype combining the absence of the 16-bp insertion and the presence of proline at codon 72 (No Ins-72Pro) was associated with an earlier age at onset of the first primary tumour in $B R C A 2$ mutation carriers in the Spanish population (Osorio et al, 2006). In this study, we have evaluated this association in a series of 2932 BRCA1/2 mutation carriers from 
the Consortium of Investigators of Modifiers of BRCA1 and BRCA2 (CIMBA) (Chenevix-Trench et al, 2007).

\section{MATERIALS AND METHODS}

\section{Patients}

A total of 2088 BRCA1 mutation carriers, 841 BRCA2 mutation carriers and 3 carriers of mutations in both genes ascertained from eight centres participating in CIMBA were included in this study (Table 1). The inclusion criteria for subjects is described elsewhere (Chenevix-Trench et al, 2007).

\section{Genotyping}

Genotypes for the two polymorphisms - Ins16bp and Arg72Pro were determined for each sample using previously described methodology (Osorio et al, 2006). In some cases, the Ins16bp SNP was genotyped by DHPLC on the WAVE HT system (Transgenomic, Omaha, NE, USA) using an acetonitrile gradient and profiles analysed with the Navigator ${ }^{\mathrm{TM}}$ software (Transgenomic), and the Arg72Pro SNP was genotyped by Taqman (Applied Biosystems, Foster City, CA, USA). Hardy-Weinberg equilibrium (HWE) for each polymorphism was tested using the likelihood ratio test among unrelated individuals. The German Consortium of Hereditary Breast and Ovarian Cancer (GCHBOC) study gave HWE $P$-values of 0.005 and 0.043 for Ins16bp and Arg72Pro, respectively; therefore, all genotypes from that patient subset were confirmed by an alternative technique (DHPLC). In addition, individuals homozygous for Ins16bp were directly sequenced. The concordance rate was $100 \%$ in both instances; accordingly, the GCHBOC mutation carriers were included in all subsequent analyses. Call rates ranged between 92 and 100\% across studies.

\section{Statistical analysis}

Haplotypes were imputed using the R-package 'hapassoc' (Burkett and McNeney, 2006). Associations of individual haplotypes with time to breast cancer or ovarian cancer diagnosis were evaluated using weighted Cox proportional hazards models, using age as the time variable (Antoniou et al, 2005). Carriers were censored at the first occurrence of breast or ovarian cancer or bilateral prophylactic mastectomy. To allow for correlations between members of the same family, Huber and White robust estimators of variance were used, considering women clustered within families (Huber, 1967). The most frequent haplotype was taken as the reference and all other haplotypes were included in the multivariate model considering the number of copies of that particular variant. Models were adjusted for ethnicity, birth cohort and centre of recruitment. The analysis considered BRCA1 and BRCA2 mutation carriers separately (Table 2) and all carriers combined (data not shown).

\section{RESULTS AND DISCUSSION}

Genotype distributions and frequencies for the Ins16bp and Arg72Pro polymorphisms are shown in Table 1. Allele frequencies were similar to those previously published (Osorio et al, 2006), and genotype frequencies were consistent with HWE, except for the carriers from GCHBOC (see Materials and Methods). Haplotypes were inferred, and haplotype- and genotype-specific hazard ratios were estimated separately for each of breast (Table 2) and ovarian cancer (data not shown), among BRCA1 and BRCA2 mutation carriers. No evidence of association was found for any of the genotypes or haplotypes analysed with either breast or ovarian cancer risk, including the No Ins-72Pro haplotype, previously reported to be associated with an increased risk to develop a first primary tumour before 35 years of age in BRCA2 mutation carriers (Osorio et al, 2006).

To confirm that this negative result was not due to the different analytic approach performed in this study, we carried out a logistic regression analysis, as was done in the original study (Osorio et al, 2006), considering those with age at diagnosis younger than 35 as cases, and did not find a positive association between early diagnosis and this haplotype. In the original study, the result was corroborated by a functional assay (Osorio et al, 2006), in which a decrease in apoptotic rate was found to be associated with the No Ins-72Pro haplotype. However, although concordant, both the genetic and the functional studies were limited by the small sample size (265 and 24 individuals, respectively), as reflected in the marginal statistically significant results described in that report.

In summary, the previously reported association of the No Ins72 Pro haplotype in $p 53$ with an increased cancer risk in BRCA2 mutation carriers (Osorio et al, 2006) has not been validated in a larger series proceeding from the Consortium of Investigators of Modifiers of BRCA1 and BRCA2 (CIMBA). In this series of 2932 BRCA1/2 mutation carriers, no evidence of modification of breast or ovarian cancer risk by any of the two polymorphisms, Ins $16 \mathrm{bp}$ and Arg72Pro, or their haplotype combinations has been detected. The lack of confirmation of a previously reported association found in a much smaller series highlights the necessity of international collaborative efforts aimed at achieving the statistical power required to reach reliable definitive conclusions in genetic association studies.

Table I Genotype distribution of the two p53 polymorphisms in the BRCAI and BRCA2 mutation carriers by participating study

\begin{tabular}{|c|c|c|c|c|c|c|c|c|c|c|}
\hline \multirow[b]{2}{*}{ Study } & \multirow{2}{*}{$\begin{array}{l}\text { Country of } \\
\text { residence }\end{array}$} & \multirow{2}{*}{$\begin{array}{l}\text { Ascertainment } \\
\text { basis }\end{array}$} & \multicolumn{4}{|c|}{ Ins I 6bp N (\%) } & \multicolumn{4}{|c|}{ Arg72Pro N (\%) } \\
\hline & & & No Ins & No Ins/I6bp Ins & I6bplns & Total & Arg72Arg & Arg72Pro & Pro72Pro & Total \\
\hline $\mathrm{CNIO}$ & Spain and Greece $\mathrm{a}^{\mathrm{a}}$ & Clinic & $335(74.12 \%)$ & $105(23.23 \%)$ & $12(2.65 \%)$ & 452 & $28 \mid(56.31 \%)$ & $176(35.27 \%)$ & $42(8.42 \%)$ & 499 \\
\hline MBCSG & Italy & Clinic & $190(65.07 \%)$ & $91(31.16 \%)$ & | | (3.77\%) & 292 & $156(50.81 \%)$ & 135 (43.97\%) & $16(5.21 \%)$ & 307 \\
\hline DKFZ & $\begin{array}{l}\text { Germany, Pakistan, } \\
\text { Colombia }\end{array}$ & Clinic & $128(74.42 \%)$ & $41(23.84 \%)$ & $3(1.74 \%)$ & 172 & $87(51.18 \%)$ & $67(39.41 \%)$ & $16(9.41 \%)$ & 170 \\
\hline $\mathrm{GCHBOC}^{b}$ & Germany & Clinic & $593(75.16 \%)$ & $17 \mid(21.67 \%)$ & $25(3.17 \%)$ & 789 & 474 (56.97\%) & $294(35.34 \%)$ & $64(7.69 \%)$ & 832 \\
\hline HEBCS & Finland & Clinic & | 48 (78.72\%) & 39 (20.74\%) & I (0.53\%) & 188 & $96(51.06 \%)$ & 79 (42.02\%) & $13(6.91 \%)$ & 188 \\
\hline $\mathrm{NCl}$ & United States & Clinic & 160 (73.06\%) & $56(25.57 \%)$ & $3(1.37 \%)$ & 219 & $96(50.26 \%)$ & $81(42.41 \%)$ & $14(7.33 \%)$ & 191 \\
\hline $\mathrm{HCC}$ & Poland & Clinic & $458(67.25 \%)$ & $202(29.66 \%$ & $21(3.08 \%)$ & 681 & $328(48.16 \%)$ & $289(42.44 \%)$ & $64(9.40 \%)$ & 681 \\
\hline Total & & & $2012(72.04 \%)$ & $705(25.24 \%)$ & $76(2.72 \%)$ & $2793^{c}$ & $15 \mid 8(52.93 \%)$ & | $12 \mid(39.09 \%)$ & $229(7.98 \%)$ & 2869 \\
\hline
\end{tabular}

Abbreviations: GCHBOC = German Consortium of Hereditary Breast and Ovarian Cancer; HWE = Hardy-Weinberg equilibrium. ${ }^{2}$ The CNIO series consisted of samples from the Spanish Consortium for the Study of Genetic Modifiers of BRCAI and BRCA2 and the NCSR Demokritos, Athens (Greece). Cases from the original study were included in the analysis (Osorio et al, 2006). ' Deviation from HWE with P-values of 0.005 and 0.043 was observed for Ins I 6bp and Arg72Pro, respectively. 'Missing genotypes are not included in the totals. Owing to technical difficulties, more failed genotypes were observed for the Ins I 6bp polymorphism. 
Table 2 Haplotype frequencies ${ }^{\mathrm{a}}$ by mutation and disease status and HR estimates for breast cancer

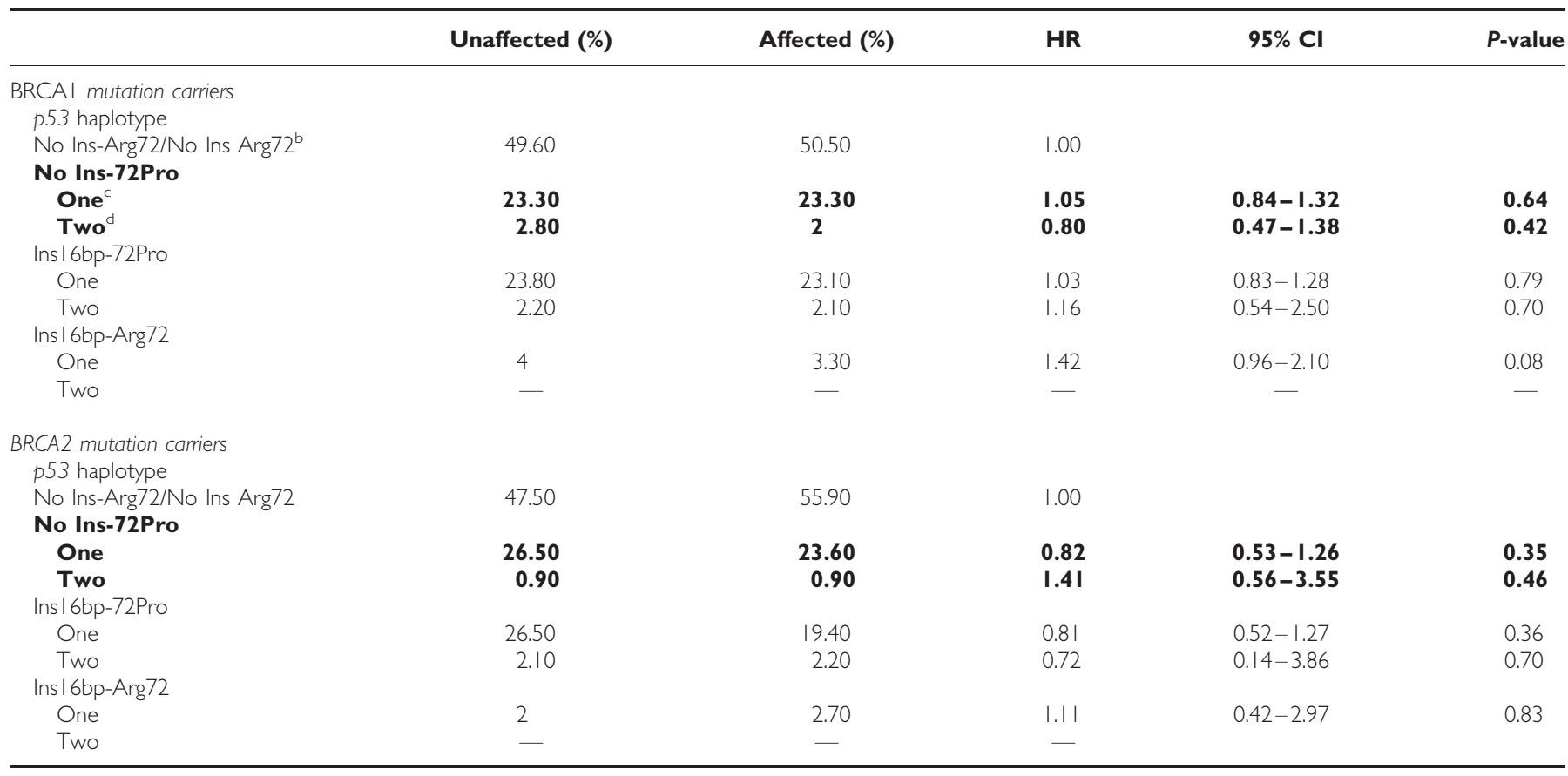

Abbreviations: $\mathrm{Cl}=$ confidence interval; $\mathrm{HR}=$ hazard ratio. HRs corresponding to the haplotype associated with increased cancer risk in the original study are in bold.

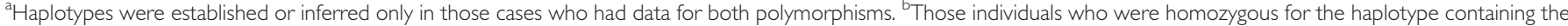
common allele for both polymorphisms were considered as the reference group. 'Individuals harbouring at least one given haplotype (heterozygous or homozygous) ${ }^{d}$ Individuals homozygous for a given haplotype.

\section{ACKNOWLEDGEMENTS}

CNIO study: we thank RM Alonso and RL Milne for their assistance. This study was partially supported by Mutua Madrileña, Genome Spain and Marato TV Foundations. The Milan study is supported by the Fondazione Italiana per la Ricerca sul Cancro. DKFZ study: we thank D Torres and MU Rashid for providing DNA samples and supplying data. AC Antoniou, $\mathrm{L}$ McGuffog and the CIMBA data management are funded by Cancer Research UK.

\section{REFERENCES}

Antoniou AC, Goldgar DE, Andrieu N, Chang-Claude J, Brohet $\mathrm{R}$, Rookus MA, Easton DF (2005) A weighted cohort approach for analysing factors modifying disease risks in carriers of high-risk susceptibility genes. Genet Epidemiol 29: 1 - 11

Baynes C, Healey CS, Pooley KA, Scollen S, Luben RN, Thompson DJ, Pharoah PD, Easton DF, Ponder BA, Dunning AM (2007) Common variants in the ATM, BRCA1, BRCA2, CHEK2 and TP53 cancer susceptibility genes are unlikely to increase breast cancer risk. Breast Cancer Res 9: R27

Biros E, Kohut A, Biros I, Kalina I, Bogyiova E, Stubna J (2002) A link between the p53 germ line polymorphisms and white blood cells apoptosis in lung cancer patients. Lung Cancer 35: 231-235

Burkett KG, McNeney BJ (2006) Software for likelihood inference of trait associations with SNP haplotypes and other attributes. J Stat Soft 16: 1-9

Chenevix-Trench G, Milne RL, Antoniou AC, Couch FJ, Easton DF, Goldgar DE (2007) An international initiative to identify genetic modifiers of cancer risk in BRCA1 and BRCA2 mutation carriers: the Consortium of Investigators of Modifiers of BRCA1 and BRCA2 (CIMBA). Breast Cancer Res 9: 104

Costa S, Pinto D, Pereira D, Rodrigues H, Cameselle-Teijeiro J, Medeiros R, Schmitt F (2008) Importance of TP53 codon 72 and intron 3 duplication $16 \mathrm{bp}$ polymorphisms in prediction of susceptibility on breast cancer. BMC Cancer 8: 32

Damin AP, Frazzon AP, Damin DC, Roehe A, Hermes V, Zettler C, Alexandre CO (2006) Evidence for an association of TP53 codon 72 polymorphism with breast cancer risk. Cancer Detect Prev 30: $523-529$
Dumont P, Leu JI, Della Pietra III AC, George DL, Murphy M (2003) The codon 72 polymorphic variants of $\mathrm{p} 53$ have markedly different apoptotic potential. Nat Genet 33: 357-365

Huber P (1967) The behavior of maximum likelihood estimates under non-standard conditions. Proceedings of the Fifth Berkley Symposium in Mathematical Statistics and Probability. The Regents of the University of California: California 1: 221-233

Jonkers J, Meuwissen R, van der Gulden H, Peterse H, van der Valk M, Berns A (2001) Synergistic tumor suppressor activity of BRCA2 and p53 in a conditional mouse model for breast cancer. Nat Genet 29: 418-425

Liu X, Holstege H, van der Gulden H, Treur-Mulder M, Zevenhoven J, Velds A, Kerkhoven RM, van Vliet MH, Wessels LF, Peterse JL, Berns A, Jonkers J (2007) Somatic loss of BRCA1 and p53 in mice induces mammary tumors with features of human BRCA1-mutated basal-like breast cancer. Proc Natl Acad Sci U S A 104: 12111-12116

Martin AM, Kanetsky PA, Amirimani B, Colligon TA, Athanasiadis G, Shih HA, Gerrero MR, Calzone K, Rebbeck TR, Weber BL (2003) Germline TP53 mutations in breast cancer families with multiple primary cancers: is TP53 a modifier of BRCA1? J Med Genet 40: e34

Ongusaha PP, Ouchi T, Kim KT, Nytko E, Kwak JC, Duda RB, Deng CX, Lee SW (2003) BRCA1 shifts p53-mediated cellular outcomes towards irreversible growth arrest. Oncogene 22: 3749-3758

Osorio A, Martinez-Delgado B, Pollan M, Cuadros M, Urioste M, Torrenteras C, Melchor L, Diez O, De La Hoya M, Velasco E, Gonzalez-Sarmiento R, Caldes T, Alonso C, Benitez J (2006) A haplotype containing the p53 polymorphisms Ins16bp and Arg72Pro modifies cancer risk in BRCA2 mutation carriers. Hum Mutat 27: 242-248 
Suspitsin EN, Buslov KG, Grigoriev MY, Ishutkina JG, Ulibina JM, Gorodinskaya VM, Pozharisski KM, Berstein LM, Hanson KP, Togo AV, Imyanitov EN (2003) Evidence against involvement of p53 polymorphism in breast cancer predisposition. Int J Cancer 103: 431-433

Wang-Gohrke S, Rebbeck TR, Besenfelder W, Kreienberg R, Runnebaum IB (1998) p53 germline polymorphisms are associated with an increased risk for breast cancer in German women. Anticancer Res 18: 2095-2099
Weston A, Pan CF, Ksieski HB, Wallenstein S, Berkowitz GS, Tartter PI, Bleiweiss IJ, Brower ST, Senie RT, Wolff MS (1997) p53 haplotype determination in breast cancer. Cancer Epidemiol Biomarkers Prev 6: $105-112$

Wu X, Zhao H, Amos CI, Shete S, Makan N, Hong WK, Kadlubar FF, Spitz MR (2002) p53 genotypes and haplotypes associated with lung cancer susceptibility and ethnicity. J Natl Cancer Inst 94: 681-690 